\title{
Effects of pretraining US density and test ITI upon the acquisition of autoshaping
}

\author{
ARTHUR TOMIE and DIANE ABBONDANDOLO \\ Rutgers University, New Brunswick, New Jersey 08903
}

\begin{abstract}
Four groups of pigeons were tested for the acquisition of autoshaping to a green key CS following 30 days of pretraining involving intermittent, unsignaled US (food) presentations. The groups were arranged in a 2 by 2 factorial design with two levels of pretraining schedule (VT $30 \mathrm{sec}$ vs. VT $90 \mathrm{sec}$ ) and two levels of test schedule (VT $30 \mathrm{sec}$ vs. VT $90 \mathrm{sec}$ ). The data revealed a main effect of test schedule such that subjects tested under the VT 90 -sec schedule acquired the keypeck CR faster than subjects tested under the VT 30-sec schedule. There was no main effect of pretraining schedule and no interaction effect between pretraining and testing schedules. Implications for theories of acquisition and retardation of autoshaping are discussed.
\end{abstract}

The acquisition of a Pavlovian CR is reliably retarded by the administration during pretraining of intermittent, unsignaled US presentations (cf. Baker \& Mackintosh, 1979; Cannon, Berman, Baker, \& Atkinson, 1975; Kamin, 1961; Mis \& Moore, 1973; Randich \& LoLordo, 1979; Siegel \& Domjan, 1971; Taylor, 1956; Chambers \& Szakmary, Note 1). This retardation effect has been extensively documented in studies utilizing the autoshaping procedure (Brown \& Jenkins, 1968). That is, pigeons given extensive experience with unpredictable presentations of food (US) are subsequently retarded in acquiring the keypecking $\mathrm{CR}$, when the illumination of the pecking key (CS) is followed by the responseindependent presentation of the food US (cf. Downing \& Neuringer, 1976; Engberg, Hansen, Welker, \& Thomas, 1972; Tomie, 1976, in press; Tomie, Murphy, Fath, \& Jackson, 1980, Wasserman, 1972; Schwartz \& Balsam, Note 2).

Different theoretical interpretations of the retardation effect in autoshaping have been set forth. For example, Engberg et al. (1972) have suggested that US-only pretraining teaches the subject that the occurrence of the US is uncontrollable. This learning produces a general cognitive associative deficit, analogous to the "learned helplessness" cognition (cf. Maier, Seligman, \& Solomon, 1969), which transfers to the autoshaping situation and interferes with the learning of the CS-US association. That is, learning that the US is uncontrollable makes it more difficult for the subject to perceive any associative relationships involving the US.

This research was supported by National Institute of Mental Health Grant MH 29425-01, National Science Foundation Grant BNS 77-20564, a Biomedical Sciences Support grant administered by Rutgers University, and Rutgers Research Council grants awarded to the senior author. Requests for reprints should be sent to Arthur Tomie, Department of Psychology, Busch Campus, Rutgers University, New Brunswick, New Jersey 08903.
An alternative theoretical account of the retardation effect is based upon the blocking phenomenon (Kamin, 1969). Kamin has noted that conditioning to a novel CS is retarded if that CS is compounded with another $\mathrm{CS}_{\mathbf{X}}$, which has been previously conditioned to the US. Moreover, the magnitude of the blocking effect is directly related to the amount of conditioning that is accrued to $\mathrm{CS}_{\mathbf{X}}$ prior to the introduction of the novel CS. Since the static background contextual stimuli are present in the conditioning environment during pretraining and paired with unsignaled US presentations, the context should be conditioned by US-only pretraining; moreover, the context should subsequently exert a blocking influence when compounded with the illuminated key CS during the autoshaping test (Tomie, 1976).

The context-blocking formulation assumes that the retardation of autoshaping reflects the degree to which the autoshaping context is conditioned at the time of testing. Several lines of evidence derived from the literature on the effects of US-only pretraining on autoshaping support this notion. Downing and Neuringer (1976) and Schwartz and Balsam (Note 2) have parametrically varied the number of pretraining US-only presentations and have observed a positive relationship between the number of unpredictable feedings and the magnitude of the subsequently observed retardation. Their data support the contex-blocking hypothesis, in that the strength of the contextt-food association should be directly related to the number of context-food pairings experienced during pretraining.

Further support is derived from the observation that the retardation effect following US-only pretraining is context specific (cf. Tomie, 1976; Tomie et al., 1980; Schwartz \& Balsam, Note 2). That is, gross alteration of the background contextual stimuli between pretraining and testing alleviates the deleterious effects of US-only pretraining upon subsequent autoshaping. Alleviation of retardation should be engendered by any manipulation 
that provides for reduction in the excitatory strength of the test context. Tomie (1976; Experiment 2) has shown that the retardation effect is alleviated by a contextextinction manipulation. That is, interpolating nonreinforced context exposure between US-only pretraining and testing (i.e., extinguishing the context) reduces the magnitude of the retardation effect.

In summary, the data indicate that the magnitude of the retardation effect induced by US-only pretraining is directly related to the excitatory strength of the test context, which is manipulated in a manner specified by straightforward conditioning considerations. That is, the excitatory strength of the context is increased by the pairing of the context with food, whereas the presentation of the context in the absence of food extinguishes its excitatory properties.

If the retarding properties of the context are a byproduct of straightforward conditioning considerations, then the degree of retardation of autoshaping should be directly related to the density of US-only presentations during pretraining. Denser schedules of unpredictable US presentations would maximize the number of contextfood pairings per unit time, while simultaneously minimizing nonreinforced context-extinction effects during the interreinforcement time. The present experiment investigates the effects of pretraining US density upon the acquisition of autoshaping.

\section{METHOD}

\section{Subjects}

The subjects were 32 experimentally naive adult pigeons obtained from a local supplier and maintained at $70 \%-75 \%$ of their ad-lib weights throughout the experiment. Subjects were housed in individual metal cages and given free access to grit and water.

\footnotetext{
Apparatus

Four standard pigeon chambers were used, with associated automatic programming and recording equipment. Each chamber measured 35 by 35 by $30 \mathrm{~cm}$ (length by width by height), with a metal intelligence panel on the front containing a 2.9-cm-diam pecking key centered $20 \mathrm{~cm}$ above a wire grid floor. Stimuli could be projected onto the response key by industrial Electronics Engineers in-line display cells equipped with GE 1815 miniature lamps and Kodak Wratten Filter 99 which provided chromatic light with peak wavelength transmission at $555 \mathrm{~nm}$ (green). The food-hopper aperture was located directly below the pecking key. A houselight was mounted behind a $2.4-\mathrm{cm}$-wide strip of white Plexiglas located above the intelligence panel; it provided ambient illumination of the conditioning chamber. Eighty-two decibels (SPL) of masking noise was provided by the exhaust fans, which were continuously operative during all phases of the experiment.

\section{Procedure}

Prior to the initiation of the experiment, the 32 pigeons were unsystematically divided into four groups of eight pigeons each. On Day 1, all subjects were trained to approach and eat from the food hopper. On Day 2, the eight pigeons in each group received the first of 30 daily sessions of pretraining, consisting of 60 presentations of 5 -sec access to a tray of mixed pigeon grain (US). Two of the groups received US presentations of a variabletime (VT) 30 -sec schedule. The remaining two groups were given grain on a VT 90 -sec schedule.
}

Following 30 days of pretraining, the 32 pigeons were tested for the acquisition of autoshaping. Autoshaping trials consisted of the illumination of the response key by a light of $555 \mathrm{~nm}$ for the $7.5 \mathrm{sec}$ immediately preceding response-independent 5 -sec access to grain. Sixty autoshaping trials were administered per session. Subjects were run for eight sessions. Half of the 16 pigeons that received US-only pretraining with the VT $30-\mathrm{sec}$ schedule were administered autoshaping trials according to a VT 30-sec schedule (Group 30-30); the remaining half of those subjects were administered autoshaping trials according to a VT 90-sec schedule (Group 30-90). In a parallel fashion, half of the 16 pigeons that received US-only pretraining with the VT 90-sec schedule were administered autoshaping trials according to a VT 30-sec schedule (Group 90-30), and the remaining half of those subjects were administered autoshaping trials according to a VT 90-sec schedule (Group 90-90).

\section{RESULTS}

The mean acquisition functions for each of the four groups of subjects are presented in Figure 1. As the figure reveals, acquisition was more rapid when autoshaping trials were administered according to a VT 90-sec schedule than when they were administered according to a VT $30-s e c$ schedule. Furthermore, the ordinal relationship among the four groups revealed in acquisition rate was retained in the acquisition asymptote. The evidence for an effect of the pretraining schedule was less impressive. Groups administered US-only pretraining according to a VT 30-sec schedule were retarded relative to the groups pretrained on a VT 90 -sec schedule; however, the differences were small and the degree of overlap among the functions was considerable.

The data from Figure 1 were entered into a 2 by 2 by 48 mixed-design analysis of variance, with pretraining schedule (VT $30 \mathrm{sec}$ vs. VT $90 \mathrm{sec}$ ), testing schedule (VT $30 \mathrm{sec}$ vs. VT $90 \mathrm{sec}$ ), and blocks of 10 trials as factors. The analysis revealed no main effect of pretraining schedule upon acquisition $(F<1)$, no interaction effect between pretraining schedule and blocks $(F<1)$, and no interaction effect between pretraining

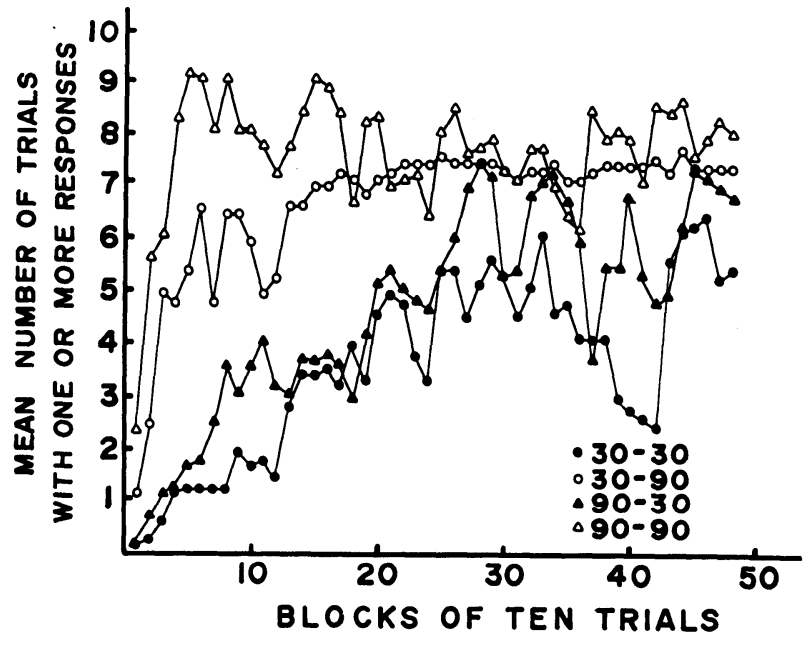

Figure 1. Mean number of trials with one or more responses as a function of 10-trial blocks for Groups 90-90, 30-90, 90-30, and $30-30$. 


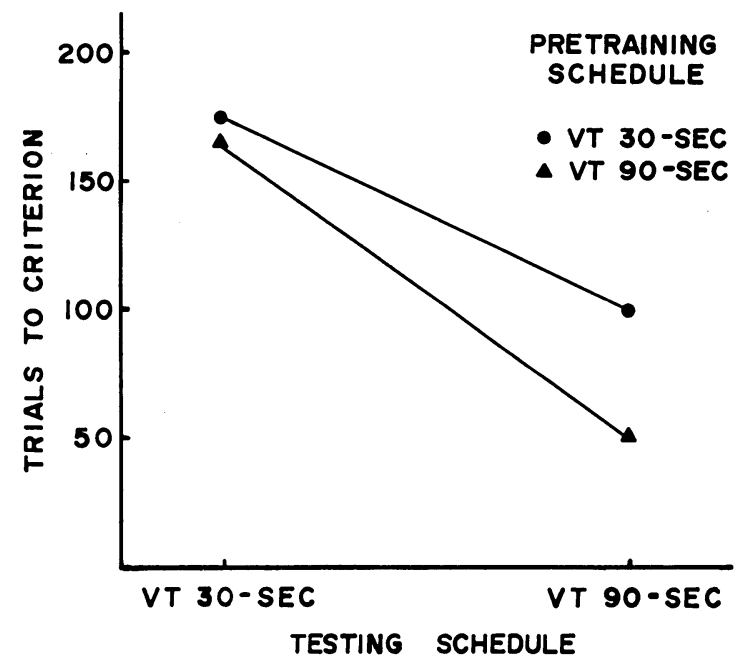

Figure 2. Mean number of trials to attain an autoshaping acquisition criterion of responding on five consecutive trials as a function of pretraining and testing schedules.

schedule and testing schedule $(\mathrm{F}<1)$. Thus, the analysis reveals no statistical support for an effect of US-only density during pretraining upon the subsequent acquisition of autoshaping. The analysis does, however, indicate that the parameter of the testing schedule had a reliable effect upon the acquisition of autoshaping, in that there was a reliable main effect of testing schedule $[F(1,28)=6.64, p<.05]$ and a reliable Testing Schedule by Blocks interaction $[\mathrm{F}(47,1316)=2.68, \mathrm{p}<.01]$.

An additional assessment of the speed of acquisition of autoshaping was provided by a measure of the number of trials required by each of the subjects to attain a criterion of responding on five consecutive trials. The mean numbers of trials to criterion for each of the four groups of subjects are presented in Figure 2, which reveals faster acquisition under the VT 90-sec testing schedule. The data were entered into a 2 by 2 analysis of variance with two levels of pretraining schedule (VT $30 \mathrm{sec}$ vs. VT $90 \mathrm{sec}$ ) and two levels of testing schedule (VT $30 \mathrm{sec}$ vs. VT $90 \mathrm{sec}$ ). The analysis revealed no main effect of pretraining schedule $(F<1)$ and no interaction effect between pretraining and testing schedules $(F<1)$; however, there was a reliable main effect of testing schedule $[F(1,28)=6.89, p<.925]$. Thus, the pattern of results identified by the analysis of the acquisition functions was precisely corroborated by the analysis of the trials-to-criterion data.

To determine whether the observed differences in acquisition asymptote (see Figure 1) were statistically reliable, a 2 by 2 by 12 mixed-design analysis of variance was performed on the data from the last two sessions (12 blocks of 10 trials). The analysis revealed no main effect of pretraining schedule $(F<1)$, but the main effect of testing schedule approached statistical significance $[\mathrm{F}(1,28)=3.50, .05<\mathrm{p}<.10]$, providing some support for the observation that the pigeons tested with a VT $90-$ sec schedule attained a higher acquisition asymptote than did the pigeons tested with a VT $30-\mathrm{sec}$ schedule.

\section{DISCUSSION}

The results support the following conclusion. Pigeons autoshape more rapidly when trials are programmed according to a VT 90-sec schedule than when trials are programmed according to a VT $30-\mathrm{sec}$ schedule, and there is a tendency for the differences in acquisition rate to carry over into asymptotic performance. There are no reliable effects upon subsequent acquisition of the density of unpredictable feedings administered via US-only pretraining, nor are there any reliable interaction effects between pretraining and testing schedules.

The more rapid acquisition of autoshaping with the longer intertrial interval (ITI) is consistent with the results of parametric investigations of ITI effects in Pavlovian conditioning (cf. Gormezano \& Moore, 1969; Kimble, 1961) and in autoshaping (cf. Gibbon, Baldock, Locurto, Gold, \& Terrace, 1977; Gibbon, Farrell, Locurto, Duncan, \& Terrace, 1980; Perkins, Beavers, Hancock, Hemmendinger, Hemmendinger, \& Ricci, 1975; Terrace, Gibbon, Farrell, \& Baldock, 1975). The direct relationship between test ITI and asymptotic probability of keypecking has been previously reported by Gibbon et al (1980) and Terrace et al. (1975). This pattern of results is consistent with a number of different theoretical formulations of the Pavlovian acquisition process (cf. Gibbon \& Balsam, in press; Gibbon, Berryman, \& Thompson, 1974; Rescorla \& Wagner, 1972). Unfortunately, however, these data provide ineffective leverage in discriminating among the theories.

The absence of an effect of the pretraining schedule is contrary to predictions derived from the context-blocking hypothesis, although it should be noted that the obtained results were in the predicted direction. Sharing in the embarassment are theoretical formulations of Pavlovian conditioning that predict a direct relationship between the excitatory associative strength of the context and the density of US presentations during pretraining (cf. Gibbon \& Balsam, in press; Rescorla \& Wagner, 1972).

One may argue that there is an effect of the pretraining schedule, but that the effect is simply less robust than that produced by the testing schedule manipulation. How does one account for the differential robustness of the pretraining and testing schedule manipulations? If the effect of the testing schedule upon acquisition is mediated by differences in the conditioning of the context during acquisition (cf. Gibbon \& Balsam, in press; Rescorla \& Wagner, 1972), these context effects should be at least as large when there is no discrete-trial CS present (i.e., as during US-only pretraining). The failure to observe the expression of differential context control as a function of pretraining schedules makes it difficult to attribute test ITI effects to that same factor. It is important to note that the Pavlovian literature, to our knowledge, contains no studies that investigate the density of unpredictable US presentations upon subsequent acquisition and that the results observed in this experiment are novel as well as unexpected.

The data reveal no evidence of an interaction between pretraining and testing schedules. That is, Groups 30-30 and 90-90 acquired keypecking at about the same rate as did Groups 30-90 and 90-30. This implies that changing the schedule parameter between pretraining and testing does not systematically influence the acquisition of autoshaping. There is some evidence from the instrumental conditioning literature that the ITI is an important contextual feature (cf. Neely \& Wagner, 1974; Sheffield, 1949), in which case one might expect greater context blocking effects in groups that experience no change in the schedule parameter. On the other hand, studies that have demonstrated control by the ITI have invariably utilized a fixed 
value, whereas, in the present experiment, the ITI parameter represents a mean value, with a great range of variability about that mean. It is not particularly surprising, therefore, to find little evidence of control by ITI in this experiment.

The acquisition rates observed for the groups tested under the $30-\mathrm{sec}$ schedule in this experiment are comparable to those reported previously for subjects administered pretraining with unpredictable food (cf. Engberg et al., 1972; Tomie et al., 1980) and retarded relative to rates typically observed for subjects tested under similar circumstances without such pretraining (cf. Engberg et al., 1972; Terrace et al., 1975; Tomie et al., 1980). On the other hand, the acquisition rates observed for the groups tested under the $90-\mathrm{sec}$ schedule in this experiment are similar to those reported for subjects with no US-only pretraining that are tested for acquisition with a $90-\mathrm{sec}$ ITI (Terrace et al., 1975). That is, US-only pretraining appears to retard acquisition on a VT $30-\mathrm{sec}$ schedule, but not on a VT $90-\mathrm{sec}$ schedule. Since the 90-sec ITI exposes the pigeon to extensive context extinction during acquisition, the absense of a retardation effect is not inconsistent with the context-blocking hypothesis (cf. Tomie, 1976, Experiment 2). The hypothesis, in fact, predicts the inverse relationship between test ITI and degree of retardation following US-only pretraining observed here.

In summary, the data provide mixed support for the contextblocking hypothesis. The effects of the test ITI and the relationship between test ITI and retardation are in accordance with the notions set forth by the hypothesis; however, the absence of a pretraining schedule effect is troublesome and questions the basic assumptions of that hypothesis.

\section{REFERENCE NOTES}

1. Chambers, B., \& Szakmary, G. A. Effects of US-preexposure on the acquisition of the CER. Paper presented at the meeting of the Eastern Psychological Association, Philadelphia, Pennsylvania, April 1979.

2. Schwartz, A. L. \& Balsam, P. D. Retardation of autoshaping following US-only pretraining. Paper presented at the meeting of Eastern Psychological Association, Philadelphia, Pennsylvania, April 1979.

\section{REFERENCES}

Bıкю. A. G., \& Mackintosh, N. J. Preexposure to the CS alone. US alone or CS and US uncorrelated: Latent inhibition, blocking by context or learned irrelevance? Learning and Motivation, 1979, 10, 278-294.

Brown. P. L., \& JENKins, H. M. Auto-shaping of the pigeon's keypeck. Journal of the Experimental Analysis of Behavior, $1968,11,1-8$.

Cinnon, D. S., Berman, R. F., Baker, T. B., \& Atrinson, C. A. Effect of preconditioning unconditioned stimulus experience on learned taste aversion. Journal of Experimental Psychology: Animal Behavior Processes, 1975, 1, 270-284.

Downing, K., \& Neuringer, A. Autoshaping as a function of prior food presentation. Journal of the Experimental Analysis of Behavior, 1976, 26, 463-469.

Enciberi, L. A., Hansen, G., Welker, R. L., \& Thomas, D. R. Acquisition of key-pecking via autoshaping as a function of prior experience: "Learned laziness"? Science, 1972, 178, 1002-1004.

Gibbon, J., Baldock, M.D., Locurto, C., Gold, L., \& Terrace, H. S. Trial and intertrial durations in autoshaping. Journal of Experimental Psychology: Animal Behavior Processes, 1977, 3, 264-284.

Gibbon, J., \& Balsam, P. D. Spreading association in time. In C. Locurto, H. S. Terrace, \& J. Gibbon (Eds.), Autoshaping and conditioning theory. New York: Academic Press, in press.

Gibbon, J., Berryman, R., \& Thompson, R. L. Contingency spaces and measures in classical and instrumental conditioning. Journal of the Experimental Analysis of Behavior, 1974, 21, 42-62.

Gibbon, J., Farrell, J., Locurto, C. M., Duncan, H. J., \& Terrace, H. S. Partial reinforcement in autoshaping with pigeons. Animal Learning \& Behavior, 1980, 8, 45-59.

Gormezano, I., \& Moore, J. W. Classical conditioning. In M. Marx (Ed.), Learning: Processes. London: Macmillan, 1969.

KAMIN, L. J. Apparent adaptation effects in the acquisition of a conditioned emotional response. Canadian Journal of Psychology, 1961, 15, 176-188.

Kamin, L. J. Predictability, surprise, attention and conditioning. In B. A. Campbell \& R. M. Church (Eds.), Punishment and aversive behavior. New York: Appleton-Century-Crofts, 1969.

KIMBLE, G. A. Hilgard and Marquis' conditioning and learning. New York: Appleton-Century-Crofts, 1961.

Maier, S. F., Seligman, M. E. P., \& Solomon, R. L. Pavlovian fear conditioning and learned helplessness. In B. A. Campbell \& R. M. Church (Eds.), Punishment and aversive behavior. New York: Appleton-Century-Crofts, 1969.

Mis, R. W., \& Moore, J. W. Effects of preacquisition UCS exposure on classical conditioning of the rabbit's nictitating membrane response. Learning and Motivation, 1973, 4, 108-114.

Neely, J. H., \& Wagner, A. R. Attention of blocking with shifts in reward: The involvement of schedule generated contextual cues. Journal of Experimental Psychology, 1974, 102, 751-763.

Perkins, C. C., Jr., Beavers, W. O., Hancock, R. A., Jr., Hemmendinger, P. C., Hemmendinger, D., \& Ricci, J. A. Some variables affecting rate of key pecking during responseindependent procedures (autoshaping). Journal of the Experimental Analysis of Behavior, 1975, 24, 59-72.

RANDich, A., \& LoLordo, V. M. Preconditioning exposure to the unconditioned stimulus affects the acquisition of a conditioned emotional response. Learning and Motivation, 1979, 10, 245-277.

Rescorla, R. A., \& Wagner, A. R. A theory of Pavlovian conditioning: Variations in the effectiveness of reinforcement and non-reinforcement. In A. Black \& W. Prokasy (Eds.), Classical conditioning. New York: Appleton-Century-Crofts, 1972.

Sheffield, V. F. Extinction as a function of partial reinforcement and distribution of practice. Journal of Experimental Psychology, 1949, 39, 511-526.

Siegel, S., \& DomJan, M. Backward conditioning as an inhibitory procedure. Learning and Motivation, 1971, 21, 1-11.

TAYLOR, J. A. Level of conditioning and intensity of the adaptation stimulus. Journal of Experimental Psychology, 1956, 51, 127-130.

Terrace, H. S., Gibbon, J., Farrell, L., \& Baldock, M. D. Temporal factors influencing the acquisition and maintenance of an autoshaped keypeck. Animal Learning \& Behavior, 1975, 3, 53-62.

Tomie, A. Interference with autoshaping by prior context conditioning. Journal of Experimental Psychology: Animal Behavior Processes, 1976, 2, 323-334.

Tomie, S. Effects of unpredictable food upon the subsequent acquisition of autoshaping: Analysis of the context blocking hypothesis. In C. M. Locurto, H. S. Terrace, \& J. Gibbon (Eds.), Autoshaping and conditioning theory. New York: Academic Press, in press.

Tomie, A., Murphy, A. L., Fath, S., \& Jackson, R. L. Retardation of autoshaping following pretraining with unpredictable food: Effects of changing the context between pretraining and testing. Learning and Motivation, 1980, 11, 117-134.

WASSERMAN, E. A. The selection and direction of behavior by predictive stimuli. Unpublished doctoral dissertation, Indiana University, 1962.

(Received for publication December 17, 1980.) 